\title{
The composition of magmatic Ni-Cu-(PGE) sulfide deposits in the Tati and Selebi-Phikwe belts of eastern Botswana
}

\author{
W. D. Maier • S.-J. Barnes • G. Chinyepi • \\ J. M. Barton Jr • B. Eglington • I. Setshedi
}

Published online: 5 January 2008

(C) Springer-Verlag 2007

Unfortunately, the tick marks of the picrite-crust mixing lines in Fig. 5 have been plotted erroneously. As a result, the correct value of crustal component is $<$ ca. $5 \%$ at Tati (not $<10-20 \%$ as stated in the text) and $>$ ca $5 \%$ at PhikweDikoloti (as opposed to $>10-20 \%$ ).

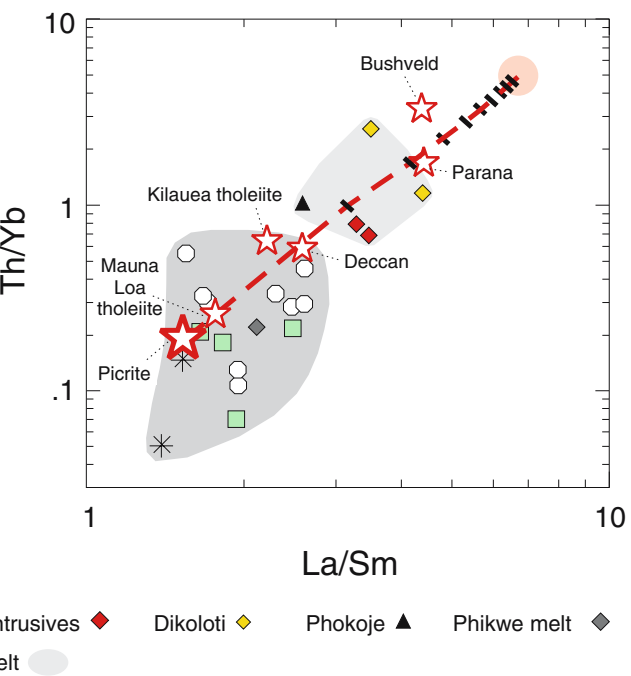

Fig. 5 Binary variation diagram of a $\mathrm{Th} / \mathrm{Yb}$ vs $\mathrm{Ta} / \mathrm{Yb}$ and $\mathbf{b} \mathrm{Th} / \mathrm{Yb}$ vs $\mathrm{La} / \mathrm{Sm}$ for Tati and Selebi-Phikwe samples with low to intermediate sulfide contents. Fields of oceanic island arcs and active continental margins in a are from Pearce (1983). Composition of average upper crust is from Taylor and McLennan (1985), model picrite from Arndt

The online version of the original article can be found at http://dx.doi. org/10.1007/s00126-007-0143-5.

W. D. Maier $(\bowtie)$

Centre for Exploration Targeting, University of Western Australia,

Crawley 6009, Australia

e-mail: wdmaier@cyllene.uwa.edu.au

\section{S.-J. Barnes}

Sciences Appliquées, Université du Québec à Chicoutimi,

Chicoutimi, Canada G7H 2B1 et al. (1993), Mauna Loa, Kilauea, Deccan, Parana and Greenland lavas from Wilson (1989), and Bushveld magnesian basalt from Barnes and Maier (2002). Mixing lines between upper crust and picrite have been calculated assuming bulk mixing

G. Chinyepi $\cdot$ I. Setshedi

Department of Geology, University of Pretoria,

Pretoria 0001, South Africa

J. M. Barton Jr

Department of Geology, Fort Hare University,

Alice 5700, South Africa

B. Eglington

Department of Geology, University of Saskatchewan,

Saskatoon, Canada 